\section{Female genital mutilation: making the case for good practice}

\author{
Geoff Debelle
}

I asked a 13-year-old girl whether she had been cut. She replied, "That's horrible isn't it", a rhetorical question to which I nodded assent. She felt that it was an appropriate question to ask, given the clinical context. The next morning I read, "Cameron in crackdown on summer surge of FGM cases" (from The Observer, Sunday 14 June 2015). New laws aimed at preventing young girls being taken abroad to undergo what the prime minister described as the "cruel and barbaric practice" of female genital mutilation (FGM) were to be "fast-tracked within weeks, amid fears that the number of cases could soar during the summer holidays". The headline and story is revealing in a number of respects: it is one of a number of articles, particularly in the lead up to the historic Girl Summit in London in July 2014, that reflect increasing community, professional and political concern over the practice of 'FGM/cutting'. It signals government determination to eradicate this practice yet does so in a tone and language that might be construed as hostile to the very communities and their activists who put FGM onto the front pages in the first place.

Later that week, I was sent a link to the West Midlands Police and Crime Panel press release, which announced that, between January and November 2014, 118 cases of FGM had been referred to the West Midlands Police, and that, while there had been "no reports to West Midlands Police of mutilation in the area", there had been some intelligence to suggest girls "are brought to Birmingham to be cut".

Is there a 'summer surge' when at-risk children and young people from practising communities are more vulnerable? Is there a risk that some of those children will be sent to Birmingham to be cut? Are these evidence-based assertions or the result of careful police intelligence? How can one distinguish truth from rhetoric? What is the situation for at-risk children in the UK? This can only be answered through continuing community action and the

Correspondence to Dr Geoff D Debelle, General Paediatrics, Birmingham Childrens Hospital, Steelhouse Lane, Birmingham B4 6NH, UK; geoff.debelle@bch. nhs.uk careful accumulation of accurate data. The paper by Hodes $e t a l^{1}$ is a fine example of the latter and does as the authors attest, provide a snapshot of FGM within the UK.

In order to provide some context for this study, I will briefly trace the relatively recent upsurge in community activism that has prompted a professional, organisational and political response to FGM. I will be selective and will not cover the classification of FGM, its adverse physical and emotional consequences and clinical management as these and other areas have been the subject of a burgeoning literature, a series of excellent recent reports, particularly from $\mathrm{UNICEF}^{2}$ and $\mathrm{WHO}^{3}$ and the review by Creighton and Hodes. ${ }^{4}$

FGM, the removal or damage of external female genitalia for no medical reason, is proscribed in the majority of countries in which it is practised. It has been illegal in the UK since 1985. Since 2003, it has been illegal for a child to be taken out of the country for the purpose of FGM. It is a violation of human rights and the UN Convention on the Rights of the Child (Article 19). It is defined as child abuse within the UK. Yet it represents a dilemma in child protection in that, despite the potential grave physical and emotional risks to the child, the practice is perceived as a responsible act by practitioners to ensure the child's rite of passage within their culture. As such, FGM is a locus for contested views on 'culture'. Korbin ${ }^{5}$ argues that failure to allow for a cultural perspective in defining abuse promotes an ethnocentric position, whereas adopting a stance of false cultural relativism in which all judgements are suspended in the name of cultural rights could expose children to risk. It is important to recognise this with FGM, not as an excuse or justification for the practice but to understand why it has persisted from antiquity in order to build preventative strategies for change.

It is salutary to trace the emergence of the movement against the practice of FGM. This was deeply rooted in wider issues surrounding community activism and control and supported by organisations such as the Foundation for Women's Health Research and Development, Africans Unite Against Child Abuse and
The Minority Rights Group, groups that remain very active in the UK. African women broke the widespread silence surrounding FGM in the 1950s and 1960s, ${ }^{6}$ a period corresponding to the emerging postcolonial discourse when the practice may have been linked with preservation of cultural identity, particularly within impoverished groups in Africa where there was the threat from the dominant culture. ${ }^{7}$ There is an association between FGM prevalence and household wealth in African communities, ${ }^{2}$ and this is likely to be more so with the additional hardships associated with immigrant status. This theme was picked up in the UK by Webb and Hartley, ${ }^{8}$ who argued that any health education initiative targeted towards FGM within practising communities must occur in the context of an overall strategy to improve their health and social welfare. This was true then as it is today.

The early efforts to prevent FGM focused on the risks to health, but in the 1980s and early 1990s, the emphasis shifted to encompass FGM as a human rights violation. ${ }^{2} 6$ With this shift in emphasis came new language, with 'female genital mutilation' replacing the term 'female circumcision'. International reports such as the Minority Rights Group Report No. $47^{9}$ and treaties such as the Convention to Eliminate All Forms of Discrimination Against Women and the UN Convention on the Rights of the Child followed, with reviews in the medical literature, ${ }^{7} 81011$ guidance from the British Medical Association ${ }^{12}$ and policy statements from the American Academy of Pediatrics. ${ }^{13}$

In the years leading up to the London Girl Summit in London in 2014, there were campaigns on both sides of the Atlantic, backed by The Guardian, and spearheaded by individual activists, survivors of FGM and organisations such as the Orchid Project and Integrate Bristol in the UK and Equality Now in the US, that 'woke up the world and forced politicians to act', through petitions and effective lobbying. In the UK, the House of Commons Home Affairs Committee laid out a compelling case for a national action plan. ${ }^{14}$ A mandatory duty for regulated health and social care professionals and teachers to report known cases of FGM in girls under 18 years of age to the police came into effect in England and Wales in October 2015. ${ }^{15}$ The Health and Social Care Information Centre established an FGM Prevalence Data Set that started in September 2014. This consists of aggregated data from monthly returns from acute hospital providers in England on all 
previously identified cases of FGM currently undergoing treatment and newly identified cases. An Enhanced Data set superseded this in October 2015, with reporting extended to other clinicians including general practitioners, midwives and mental health clinicians. There is also a requirement for the 'relevant FGM information' on a female infant born to a mother with FGM to be recorded in the Parent Health Record (Red Book).

In November 2013, the Royal College of Obstetricians and Gynaecologists, the Royal College of Midwives, the Royal College of Nursing, Equality Now and the Unite union produced a document, ${ }^{16}$ endorsed by the Royal College of Paediatrics and Child Health, which merged key points from several existing guidelines. This reiterated that FGM is a form of ritual child abuse and made recommendations on sharing information between agencies, data collection and professional care for girls and young people affected by this practice. Creighton and Liao $^{17}$ criticised the document for its failure to provide a detailed action plan, an explicit time frame and mechanisms for monitoring effectiveness, thereby falling short in spelling out 'what' without offering 'how', a deficit noted in other guidance. For example, there is little current guidance on what action, if any, police, social service or health should take for an unaffected female child born to a mother who has undergone FGM. Should she be examined, and if so, how, when, how often and by whom?

Does the paper by Hodes et $a l^{1}$ shed light on these and other issues surrounding FGM? Despite being a relatively small case series, it provides the first glimpse of FGM in the UK that accurately reflects the wider picture within the broader practising communities. They studied the first 47 cases of children $<18$ years of age referred with suspected FGM to a tertiary safeguarding clinic in an inner London teaching hospital from June 2006 to May 2014. The number of referrals rose sharply in the period since the start of 2013, possibly reflecting the upsurge in activism surrounding FGM in the UK. There were 27 confirmed cases of whom 20 consented to examination: 11 had undergone type 4 FGM (WHO classification-see appendix of their paper), with 6 having evidence of such on genital examination and 5 having undergone genital pricking or nicking, confirmed by testimony only. There were eight cases of type 2 FGM and two of type 1 FGM. There were no cases of type 3 FGM. Many of the examinations findings fell between the
WHO types. In the remaining 20 cases, there was no history, testimony or findings.

The authors draw three important conclusions from these findings. First, signs of type 4 FGM may be difficult to detect and may be missed by less experienced examiners. Second, a normal examination does not exclude the possibility that FGM has taken place. Third, there are limitations to the WHO classification of FGM and that, instead, emphasis should be placed on a thorough description of findings. These are important findings with respect to training of health professionals and establishing a specific service for the assessment of children at risk of FGM.

In addition to the prominence of type 4 FGM in their series, the authors found that the majority of cases were performed at an early age and that, in the 27 confirmed cases, there were indications that some form of 'medicalisation' had taken place in 17 . These findings reflect international trends and have been attributed to the early decades of advocacy that centred on delivering a message about the health risks of FGM. ${ }^{2} 3$ In half of the countries with available data, the majority of girls are cut before the age of 5 years, with at least $80 \%$ cut between the ages of 5 and 14 years. $^{2} 3$ There is conjecture that this trend towards an earlier age for cutting might relate to a belief that the procedure will be easier to perform and therefore less harmful and that the young child might not be capable of comprehending the nature of the procedure. ${ }^{18}$ There is also a trend towards 'less severe cutting' in some countries. ${ }^{2}$

This apparent, linked trend towards type 4 FGM and increasing medicalisation has had powerful advocates, ${ }^{2} 419$ arguing that a safe, sanitised environment with medical assistance will reduce pain and complications, with a ritual 'nick, securing the necessary rite of passage for the child'. ${ }^{19}$ Numerous medical associations and UN agencies have condemned the medicalisation of FGM as legitimising and institutionalising the procedure. It is illegal to do so in the UK and in many other jurisdictions. Proponents of medicalisation argue that this stance endangers the lives of innocent girls. ${ }^{19}$ This might well become the next contested area.

The authors note the huge disparity between the number of girls estimated to be at risk of FGM in the UK and the relatively low number of cases seen in their clinic. They concluded that "this represents a failure to protect girls who are UK citizens and a largely hidden burden of safeguarding, medical and psychological problems in the paediatric population".
That might well be so but they give a more generous interpretation of this apparent discrepancy in their discussion by suggesting that it might instead represent a real reduction in the number of procedures or a trend towards type 4 FGM that is more difficult to detect.

The prevalence of FGM in the UK is likely to be difficult to determine due to its hidden nature. Using 2011 census data, and extrapolating from prevalence figures for FGM from country of origin, it has been estimated that 65000 girls aged 13 years and under are at risk of being cut. $^{1420}$ Is this an overestimate or underestimate? There has been a slow decline in the prevalence of FGM in some countries, particularly in low-prevalence counties such as Kenya. ${ }^{2}$ In addition, there is a generational shift in attitude away from FGM that is particularly discernible in younger men. ${ }^{2}$ These findings were replicated in a study undertaken by trained members of the practising communities in Birmingham between September 2010 and January 2011. ${ }^{21}$ Yet, during the period September 2014 to March 2015, 60 newly identified cases of FGM under the age of 18 years were notified nationally. $^{22}$ There may well be 'cutters' in London, Birmingham and Leeds and in other centres as police intelligence suggests. Hodes et $a l^{1}$ found that in 10 of their 27 confirmed cases of FGM, the circumstances were either known or suspected of being illegal. However, we are still awaiting a successful prosecution. ${ }^{20}$

Thus, the true situation for FGM in the UK remains hidden, despite best efforts from those within communities and other bodies, governmental, statutory and third sector. The current British Paediatric Surveillance Unit (BPSU) study, supported by Royal College of Paediatrics and Child Health (RCPCH) and funded by the Department of Health, may help to shed some light. Efforts at prevention include the Department of Health's FGM Prevention Programme, the issue of a 'Health Passport' to be discreetly carried in a purse or passport, warning that British residents can face up to 14 years in jail if they arrange for FGM to be carried out abroad, Project Azure in London, Operation Sentinel in Birmingham, Integrate Bristol, the National Society for the Prevention of Child Abuse and Neglect (NSPCC) FGM Helpline and many others.

What can paediatricians do? The study by Hodes et $a l^{1}$ is an exemplar. First, do no harm. This study sets the right tone in its child rights approach and the language used. While misplaced concern for cultural sensitivities should not override 
concern for the human rights of an individual, ${ }^{14} 20$ it is important to use language that will not compromise the dignity of the very women and children we are trying to help. ${ }^{23}$

Paediatricians should ensure that an entry is made into the Parent Health Record of any female born to a mother who has undergone FGM. They should be aware of the at-risk indicators for FGM in a girl or a young person, ${ }^{24}$ be prepared to ask questions such as 'have you been cut' and to come to a reasonable judgement of risk. There are a number of education and learning opportunities available, including the e-FGM educational programme, ${ }^{25}$ developed by Health Education England's e-Learning for Healthcare and provided free to all healthcare professionals. This programme is supported by the $\mathrm{RCPCH}$ and many other organisations.

If a paediatrician is concerned that a child has undergone FGM or is at risk for FGM, they should refer to a statutory body that will arrange for the child to be formally examined. Creighton and Hodes ${ }^{4}$ emphasise that signs of FGM may not be obvious on genital inspection and that the examination should be performed in a sensitive and gentle manner in an age-appropriate setting by examiners with the necessary core and case-specific competences for such an examination, including using a colposcope for photodocumentation and access to peer review.

This is the gold standard, provided by Hodes et $a l,{ }^{14}$ to which we should aspire. This may require discussion with commissioners to establish a service at local, regional or supraregional level, depending on need, a need that is difficult to accurately determine. By undertaking such actions, paediatricians will assist the prac- tising community in the prevention of human rights violation, the practice of FGM.

Competing interests The author is a member of Birmingham Against Female Genital Mutilation (BAFGM), a subgroup of Birmingham Children Safeguarding Board. He is Officer for Child Protection, RCPCH and chairs its Child Protection Standing Committee. The views expressed in this article are not necessary those held by these organisations. He is one of the applicants for a BPSU study on FGM, funded by the Department of Health.

Provenance and peer review Commissioned; internally peer reviewed.

To cite Debelle G. Arch Dis Child 2016;101:207209.

Received 5 July 2015

Accepted 15 December 2015

Published Online First 14 January 2016

\section{Sinked}

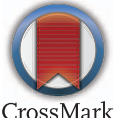

- http://dx.doi.org/10.1136/archdischild-2014-307234

- http://dx.doi.org/10.1136/archdischild-2015-308243

Arch Dis Child 2016:101:207-209.

doi:10.1136/archdischild-2015-308644

\section{REFERENCES}

1 Hodes D, Armitage A, Robinson K, et al. Female genital mutilation in children presenting to a London safeguarding clinic: a case series. Arch Dis Child 2016;101:212-6.

2 UNICEF. Female Genital Mutilation/Cutting: a statistical overview and exploration of the dynamics of change.New York: UNICEF, 2013.

3 World Health Organisation. An update on WHO's work on female genital mutilation (FGM). Geneva: World Health Organisation, 2011.

4 Creighton SM, Hodes D. Female genital mutilation: what every paediatrician should know. Arch Dis Child 2016;101:267-71.

5 Korbin JE. Cross-cultural perspectives and research directions for the 21st century. Child Abuse Negl 1991;15:67-77.

6 Althaus FA. Female circumcision: rite of passage or violation of rights? Int Fam Plan Perspect 1997:23:130-3
7 Toubia N. Female circumcision as a public health issue. New Eng J Med 1994;331:712-16.

8 Webb E, Hartley B. Female genital mutilation: a dilemma in child protection. Arch Dis Child 1994;70:441-4.

9 McLean S, Graham SE. Female Circumcision, Excision and Infibulation. The Minority Rights Group Report No 47. Second revised edn. London, 1995.

10 Black JA, Debelle GD. Female genital mutilation in Britain. BMJ 1995:310:1590-7.

11 Barstow DG. Female genital mutilation: the penultimate gender abuse. Child Abuse Negl 1999:23:501-10.

12 BMA. Female Genital Mutilation: caring for patients and child protection. BMA, 2001 (updated July 2011).

13 Davis DS, Committee on Bioethics. Policy Statement —ritual genital cutting of female minors. Pediatrics 2010;125:1088-93.

14 Female Genital Mutilation: the case for a national action plan. Second report of Session 2014-15. House of Commons, TSO, 2014.

15 Serious Crime Act, UK Government, 2015

16 Tackling FGM in the UK. Intercollegiate recommendations for identifying, recording and reporting. London: The Royal College of Midwives, 2013

17 Creighton SM, Liao L-M. Tackling female genital mutilation in the UK. BMJ 2013;347:f7150.

18 Hernlund Y. Cutting without ritual and ritual without cutting: female "circumcision" and re-ritualisation in the Gambia. In Shell-Duncan B, Hernlund Y, eds. Circumcision in Africa. Culture, Controversy and Change. Boulder: Lynne Rienner, 2000:235-52.

19 Ahmadu F. Rites and Wrongs: an outsider/inside reflects on power and excision. In Shell-Duncan B, Hernlund $Y$, eds. Circumcision in Africa. Culture, Controversy and Change. Boulder: Lynne Rienner, 2000:283-12.

20 Bindel J. An Unpunished Crime: the lack of prosecutions for female genital mutilation in the UK. London: The New Culture Forum, 2014.

21 Palfreyman A, Brown E, Nam S. Understanding female genital mutilation in Birmingham; Findings from a PEER Study. London: Options UK and Birmingham \& Solihull Women's Aid, 2011.

22 The Female Genital Mutilation Dataset (IS 1610). hscic, 30 April 302015

23 Do No Harm. The Girl Generation, September 2014.

24 Female Genital Mutilation Risk and Safeguarding. Department of Health, 2015

25 http://www.e-Ifh.org.uk/programmes/femalegenital-mulitation 